\title{
Examining the Oral Health of Filipinos: Policy Analysis
}

\author{
Michael Antonio F. Mendoza, DDM, MA,, ${ }^{1,2}$ Ma-Ann M. Zarsuelo, RND, MSc, ${ }^{1,3}$ \\ Leonardo R. Estacio Jr., MCD, MPH, PhD1,4 and Ma. Esmeralda C. Silva, MPAf, MSPPM, PhD ${ }^{1,5}$ \\ ${ }^{1}$ University of the Philippines Manila Health Policy Development Hub \\ ${ }^{2}$ College of Dentistry, University of the Philippines Manila \\ ${ }^{3}$ Institute of Health Policy and Development Studies, National Institutes of Health, University of the Philippines Manila \\ ${ }^{4}$ College of Arts and Sciences, University of the Philippines Manila \\ ${ }^{5}$ College of Public Health, University of the Philippines Manila
}

\begin{abstract}
Background. High prevalence of oral health problems persists across all age groups among Filipinos despite the continued endeavors of the government and professional societies. This position statement aimed to generate consensus policy recommendations to protect and promote oral health in the Philippines as an integral part of the healthcare service in light of the Universal Health Care (UHC) Act.
\end{abstract}

Methods. An evidence-based policy brief and presentations of dental and policy experts were used as discussion points in the roundtable discussion conducted by the UP Manila Health Policy Development Hub. Key stakeholders from various sectors were convened to generate inputs for policy actions and amendments to oral healthrelated policies.

Results. Thematic analysis of the discussion was organized using the WHO Building Blocks of Health Systems, which yielded practical, accessible, and population-wide interventions (2010). The following issues were highlighted: (a) health service delivery needs strong collaboration of LGUs; (b) insufficient workforce of dental professionals; (c) market availability of sufficiently fluoridated toothpaste per age group; and (d) health financing scheme on oral health services.

Conclusion and Recommendations. With the shift in the health system landscape brought by the UHC Act, timely and responsive inter-sectoral interventions, focusing on prevention, must be set to attain the target decrease in the prevalence of dental caries. It was also to recommend to (i) engage the academe and training institutions to increase the workforce, (ii) consider adopting international standards on sugar consumption as appropriate, and (iii) ensure sufficient funds for sustainability of oral health programs, particularly school-based caries prevention program starting in pre-schools.

Key Words: oral health, public interventions, health service delivery, dental workforce

\section{INTRODUCTION}

Corresponding author: Ma-Ann M. Zarsuelo, RND, MSc UP Manila Health Policy Development Hub

National Institutes of Health

University of the Philippines Manila

623 Pedro Gil St., Ermita, Manila 1000, Philippines

Email: mmzarsuelo@up.edu.ph
Oral health is recognized as an integral and indivisible component of every Filipino's total health since nourishment begins in the oral cavity. However, it is usually ranked last in an individual's priority. ${ }^{1}$ The National Monitoring and Evaluation Dental Survey (NMEDS) conducted by the Department of Health in 2011 shows that the prevalence of dental caries (cavities) among Filipinos is $87.4 \%$, while $48.3 \%$ for periodontal disease. This high rate is seen across all age groups. ${ }^{2}$ This is consistent with the prevalence of dental caries in the South-East Asia Region of the WHO members states, affecting $70 \%$ to $95 \%$ of school-aged children and the majority of adults. ${ }^{3}$ The prevalence of dental caries is greatly attributed to increased access to sugar, and tooth 
decay is more rampant in transitional economies due to lower prioritization of extensive care. ${ }^{4}$

Republic Act No. 9484, or "The Philippine Dental Act of 2007," guides the State in developing and nurturing competent, productive, morally-upright, and well-rounded dental professionals. The Act provides for the regulation, control, and supervision of the practice of dentistry, dental hygiene, and dental technology in the Philippines through giving of licensure examinations and stipulating penalties for infractions of the Act and other laws under its provisions. This is the first dental Act that recognizes dental hygiene and dental technology as dental professions and their importance in nation-building. The Philippine Dental Act of 2007 focuses on the scope of practice of the dental professions. Public oral health programs and directives on the provision of both private and public oral health services are not stated. ${ }^{5}$

The government endeavors to address oral health problems with the policies such as the DOH AO 2007-0007 or the 'Guidelines in the Implementation of Oral Health Program for Public Services' which covers oral health packages across all life stages, from pregnant mother up to elderly; and the DepEd DO 73, s. 2007 or the Promoting Oral Health in Public Elementary Schools. ${ }^{6,7}$ While the collaborative initiatives from different government agencies and other sectors continue, the high prevalence of oral diseases persists. An Oral Health Summit in 2013 spearheaded by the Board of Dentistry of the Professional Regulation Commission (PRC), the Philippine Dental Association (PDA), and the College of Dentistry, University of the Philippines Manila, was attended by representatives from various government agencies, the academe, research institutions, and nongovernmental partners to discuss the issues that confront oral health in the Philippines. The need for urgent and responsive inter-sectoral actions to protect and promote the oral health of all Filipinos was agreed upon. ${ }^{8}$

In the WHO Strategy for Southeast Asia 2013-2020, five priority action areas with several optional indicators were presented for a member state to adopt relevant to their country context and national objectives. These are (i) integrating oral diseases into prevention and control of NCDs, (ii) addressing oral cancer, (iii) promoting oral health through fluorides, and (iv) increasing and diversifying the oral health workforce. ${ }^{3}$

Integrating oral health in NCD context has been in policy momentum given its reciprocal link, and they share the same modifiable risk factors such as tobacco and alcohol use, unhealthy diets, and socio-economic determinants., Hence, the approach of fully integrating oral health into NCD prevention and control could be of advantage, yielding broader health strategies. ${ }^{8}$

\section{METHODS}

In line with the commitment of the UP Manila Health Policy Development Hub to be the think tank and network of health policy stakeholders, a round table discussion on oral health was conducted, which aimed to identify broadstroke implementable strategies towards improving the oral health status of Filipinos. To provide background knowledge on the current policy issues, the topic presentations were as follows: current "Oral health policies" and "The Philippine oral health situation" by the faculty members of the College of Dentistry, UP Manila; and the existing "International and local oral health systems" from a faculty member of the College of Public Health, UP Manila. Gaps and challenges presented framed the discussion points to generate the consensus policy recommendations that may guide the course of action to improve oral health in the Philippines. Program managers and coordinators of national government agencies, dentistry and health policy academicians, professional societies, and non-government organizations were convened to discuss policy issues and to arrive at a consensus agreement on the policy statement for oral health.

Inputs from the discussants focused on satisfying the following discussion questions:

1. What is the state of the implementation of the Philippine Dental Act of 2007 and other oral health policies in the country?

2. What are their strengths and weaknesses?; and

3. What policy amendments or recommendations can we draw to improve the Philippine Dental Act of 2007 and other oral health policies?

Inputs from the policy discussion were thematically analyzed using the World Health Organization's Building Blocks of Health Systems (2010) as sub-themes. ${ }^{10}$ Scientific, legislative and expert evidence from the pre-work research to the discussion was utilized as inputs for the position statement, wherein the draft was circulated back to all participants for their inputs and/or approval. This guarantees consensus insights and recommendations for practical, accessible, and population-wide short-term and longterm interventions.

With the recent enactment of the Universal Health Care (UHC) Act that aims to provide comprehensive, affordable, accessible, and quality health services among all Filipinos, related provisions were discussed to give direction to the anticipated changes in the health care system, including oral health services.

\section{RESULTS AND DISCUSSION}

\section{Health Service Delivery}

The National Policy on Oral Health $(\mathrm{NPOH})$ issued by the $\mathrm{DOH}$ in 2003 mandated local government units (LGUs) to implement Oral Health Programs and covers policies and guidelines that apply to all government and non-government health institutions whose functions and activities contribute to the improvement of oral health. ${ }^{1}$ The NPOH was supplemented by Administrative Order 2007-0007 specifying the guidelines in the implementation 
of oral health programs for public health services to reduce the prevalence rate of dental caries and periodontal diseases through a Life-Cycle Approach.

To target school-age children, the Department of Education (DepEd) undertook a Memorandum of Understanding (MOU) with the League of Provinces of the Philippines and Fit for School Inc. in 2009 for a nationwide implementation of the Essential Health Care Program (EHCP). ${ }^{11}$ EHCP focuses on dental caries, infectious diseases (respiratory tract infections and diarrhea), and worm infestations as the most basic hygiene deficiency-related infectious diseases in public schools due to lack of water and functional sanitary facilities. The program includes the following interventions: (1) daily handwashing, (2) daily toothbrushing with a fluoridated toothpaste, and (3) biannual deworming of all children. These are seen to be the most cost-effective, evidence-based preventive interventions to improve the health of school children in public schools and thereby improving their academic performance. According to DepEd Order No. 73, s. 2007, a Memorandum of Agreement was signed between DepEd and the PDA on 2011 January 30 for the nationwide implementation of the project "Happy Smiles for Healthy Kids." It aims to enhance the development of oral health habits, personal hygiene, dental health services, and oral health education/promotion. ${ }^{12}$

NMEDS (2011) data show that at age five, caries prevalence is $87.7 \%$, which has an impact on permanent dentition that starts erupting around the age of $6 .^{2}$ If a population-based program will be implemented through primary schools, the intervention might be too late since dental caries might have already developed. Currently, Smile Pilipinas Foundation, in collaboration with the Philippine Pediatric Dental Society, Inc., has a campaign called Unang Ngipin Patibayin that promotes early health care maintenance, starting at the child's $6^{\text {th }}$ month. However, the issue that developing dental caries is a behavioral noncommunicable disease puts this into question. It was further challenged to adhere to the NOHP, wherein early prevention should start at the prenatal stage in which the importance of oral health must be inculcated to pregnant mothers until it manifests into practice. Added to this, medical professionals such as obstetrician-gynecologists and pediatricians play a crucial role in the achievement of the goal.

The early intervention approach not only calls for an inter-professional approach but also delineates the responsibility to the rural health units, which must be equipped with sufficient and competent oral health professionals. Should rural health workers be involved in educating mothers, comprehensive training on oral health must be required for all rural health workers.

It must also be noted that dental services are generally expensive as it is material- or equipment-based leading to non-utilization of such services. For a country with a high poverty incidence, this forces the public to seek alternative treatments, further raising safety issues. ${ }^{13}$

\section{Health Workforce}

Fostering the development of the dental professions include the development of continuing dental education and research in the country. With the implementation of Republic Act No. 10912, otherwise known as the "Continuing Professional Development Act," dental professionals are mandated to take additional formal and non-formal training for continuing professional development and the renewal of their licenses. The enforcement of the Code of Ethics also establishes the means of doing what is right, fair, and honest in the dental professions.

The commitment of the State to address health workforce shortage and maldistribution is seen in the UHC Act. Capacity building for allied and health-related professionals would be strengthened, propelled by the PRC, $\mathrm{DOH}$, and duly registered professional societies. ${ }^{14}$

Statistics show that the Philippines has a 1:53,000 dentist to population ratio, clearly showing a shortage in service providers. ${ }^{15}$ Besides, oral health auxiliaries such as dental aides and dental hygienists are not well established in the country. There is a consensus that there is a need to capacitate a larger workforce through a more comprehensive oral health program to other health professionals such as midwives and nurses, who are the active key public health actors in the community. Nevertheless, it is essential to note that only dentists can diagnose oral health diseases and initiate treatment. This demonstrates that investing in prevention should still be the focus of oral health strategies.

The shortage of dentists and high oral health demands in the country were recognized by the State as explicitly stated in the UHC Act. Health professionals were defined in the law as "may be a doctor of medicine,... dentist, or other allied professional or practitioner duly licensed to practice in the Philippines." ${ }^{14}$ Ensuring the sustainability of the health workforce was stipulated in Section 23. National Health Human Resource Master Plan, wherein the "provision of policies and strategies for the appropriate generation, recruitment, retraining, regulation, retention, and reassessment of health workforce based on the population needs." Further, it was stated that "to ensure continuity in the provision of the health programs and services, all health professionals and health care workers shall be guaranteed permanent employment and competitive salaries. ${ }^{14} \mathrm{~W}$ ith the strengthened policy of pooling and financing health personnel, it is hoped that the oral health of the Filipinos will significantly improve.

There is a current dearth in the number of schoolbased dentists to address the oral health needs of schoolage children. One discussant from the academe shared that the ratio of DepEd dentist to students is $1: 25,432$ as of the academic year 2017-2018. This raised questions if there is a need for dentists to tend to essential dental services that focus on treatment, or should activities be refocused in developing the technical competencies of the dental team. As the dentists must be capacitated to be able to plan, implement, monitor and evaluate responsive oral health programs in their locality, 
the dental ancillaries must likewise be trained to perform basic preventive strategies such as oral health education, nutrition counseling with a focus on limiting sugary foods and beverages, toothbrushing instructions and topical fluoride application under the supervision of the dentist.

Maldistribution of dentists and other oral health professionals has been evident throughout the years being concentrated in urban areas while others seek emigration for employment. The identified short-term intervention to this geographical maldistribution of oral health professionals is to incentivize public dentist salaries to be at par with private practice. The Return Service Agreement in the UHC Law that would require recipients of government-funded scholarship programs in allied and health-related courses, including dentistry, to serve in priority areas for at least three years is expected to address this. ${ }^{11}$ Refocusing the oral health programs and strategies to a preventive approach may be a long-term solution on the lack of oral health professionals in the public sector as the impact of the programs will have a wider reach compared to individually-treating oral health needs of the population. The possibility of a public-private partnership between LGUs and dentists is also an option to consider in the delivery of oral health services. One participant raised that this collaboration was seen in a current collaboration in the province of South Cotabato, wherein municipalities with budgetary constraints band together to share a dentist.

Moreover, the PRC recognized the need for community involvement as it allocated 10\% of earned CPD units required to renew one's professional license to be community service. Though PRC Resolution No. 2019-1146 amended this, wherein one is only required to comply with an equivalent to 15 credit units, Section 25.d of the UHC Law mandates the CHED, PRC, and $\mathrm{DOH}$, in coordination with the professional societies, to reorient medical and allied medical professional education, certification and regulation towards producing health workers with competencies in the provision of primary care services. ${ }^{14,16}$

The role of the academe in response to strengthening the availability of human health resources was emphasized. One of the current endeavors of the College of Dentistry of the University of the Philippines Manila (UPCD) is to evaluate the feasibility of offering a ladderized curriculum for Doctor of Dental Medicine (DDM): starting with a dental aide, to a dental technician, to a dental hygienist, and eventually to a degree in DDM. Concurrently, there is a Commission on Higher Education (CHED) mandate for UPCD to increase enrollment for aspiring dental students. As the lone state university or college (SUC) offering the DDM program, a discussant from UPCD shared that the College is likewise aiding CHED in developing dental schools in SUCs in the Visayas and Mindanao.

As a long-term solution to augment the lack of dental professionals, broadening the Return Service Agreement (RSA) to private universities can be considered. Currently, only UPCD implements an RSA that requires DDM graduates to practice dentistry in the Philippines for two (2) years upon graduation and obtaining a license to practice. Given the weight of the RSA across all universities and the possible discord among the stakeholders, this may need a national policy to be fully implemented.

In line with the production of the workforce, the current state of dental education focuses more on clinical competence over the public health discipline. This may make the dental graduates give more emphasis on curative means rather than prevention. Thus, it is timely to consider modifying the way dentistry is taught and how the graduates are evaluated for licensure. Several small steps are accomplished to achieve this. Dental Public Health is now a recognized dental specialization by the PRC and the Philippine Academy of Dental Public Health, Inc. (PADPHI) as its accredited professional organization. PADPHI has started to regularly organize a summit of faculty members teaching Community Dentistry across universities with the intent to improve and standardize the manner Community Dentistry courses are being offered. PADPHI likewise recommended and the CHED agreed to change the name "Community Dentistry" to "Dental Public Health" for applicable courses in the dental curriculum as the term is more reflective to the competencies in the planning, implementation, monitoring and evaluation of population-based oral health programs as seen in current literature.

In line with the move to shift the clinicallyfocused curriculum to dental public health, the DOH is considering collaboration with the academe in providing pediatric dentistry as part of developing competencies for community-based practice. In support of the demand for the workforce, other learning institutions such as the Technical Education and Skills Development Authority (TESDA) are also seen as a potential provider of training to produce competent dental professionals.

This academic initiative and reorientation of dentists and other oral health professionals would be in alignment with the aim of the UHC Act to strengthen the primary health care and address the inequity of health services in the country. As for the Return Service Agreement, the final Implementing Rules and Regulations will set clear operationalization of the stipulation in Section 26 wherein "all graduates of allied and health-related courses who are recipients of government-funded scholarship programs shall be required to serve in priority areas in the public sectors for at least three full years, with compensation, and under the supervision of the DOH." ${ }^{14}$ It is important to note, though, that details on the operationalization will be presented in Implementing Rules and Regulations and could be further supplemented by other policies that will direct each government agencies on implementation, monitoring, and evaluation roles.

With oral health recognized as part of primary care, dentists, as part of the health care provider network in the implementation of UHC may also be considered to 
be primary care providers ( $\mathrm{PCPs}$ ) as they may have initial contact to patients seeking care that may need to be referred to other health care providers for other presenting conditions.

\section{Health Information Systems}

Access to Philippine oral health-related statistics has been difficult due to the unavailability of recent data or the absence of an effectively implemented data monitoring system. Health information systems of various agencies involved in the improvement of oral health must be developed to improve the monitoring and evaluation of oral health programs. The scope should further include information on dental personnel, funding, and facilities available for dental programs.

These challenges are expected to be mitigated through the implementation of Sec. 36 of the UHC Act wherein "All health service providers and insurers shall maintain information systems including enterprise resource planning, human resource information system, electronic health records, and electronic prescription consistent with DOH standards which shall be electronically uploaded regularly through interoperable systems: Provided, That the said Health Information System should be developed and funded by the DOH and PhilHealth: Provided, further, That patient privacy and confidentiality shall at all times be upheld, in accordance with the Data Privacy Act of 2012." ${ }^{14}$ Conclusiveness and interoperability of the health information will pave way to easy access to data as crucial inputs for timely interventions and researches for improvement of programs.

The regular conduct of dental epidemiologic studies must also be assured, such as the conduct of NMEDS, which is expected to be done once every five years. For $\mathrm{DOH}$, monitoring and evaluation of the oral health programs rely on the oral health indicators in NMEDS and the Field Health Services Information System (FHSIS) reports (i.e., number of children with dental caries, number of Orally Fit Children, etc.).

It is also recommended to explore the use of the International Caries Detection and Assessment System (ICDAS) in recording dental caries. ICDAS is an integrated system for measuring dental caries, and a part of the more comprehensive system called the International Caries Classification and Management System (ICCMS). The degree of disease progression can be assessed and recorded, and planning for treatment (if necessary) would be more appropriate logistically. This would also support a more preventive approach to oral health rather than a treatmentbased approach to oral health.

\section{Access to Essential Medicines}

Fluoride is widely documented for its caries preventive properties that fluoridation has been attributed as a top public health program resulting in caries decline globally. Hence, the most cost-efficient fluoride vehicle must be identified as deemed appropriate based on the local context. Options ranged from "community fluoridation of water, salt or milk; fluoridation of toothpaste; and application of fluoride varnishes or gels at an individual level, ${ }^{3}$ In the Philippines, toothpaste is the most common vehicle of fluoride administration. Hence, it must be affordable and available to all at the right quality and quantity with fluoride levels monitored to be at least 1,500 ppm (parts per million). It was raised that toothpaste manufacturers be incentivized with tax exemptions to supply lower priced fluoridated toothpaste nationwide through PhilHealth and channeled to LGUs and DepEd.

Consequently, this could serve as a platform for capitalism gains and must likewise be addressed. However, based on the experience of the Department of Community Dentistry of UPCD, generic fluoridated toothpaste is more recommended for mothers and children to be included in the EHCP of DepEd due to cost issues. Nonetheless, should fluoridated toothpaste be available to the public, LGUs and schools should be equipped with sufficient technical and physical resources to ensure that the optimal quality of the product is maintained from acquisition to distribution of the product.

Similarly, the discussants emphasized that the feasibility of this cost reduction is firmly hinged on the efficiency of implementation. To sustain the intervention, the provision of dental packages at primary schools must be anchored on DOH policies with sufficient funding and well-established central procurement. The nationwide scale of program monitoring and evaluation would face interrelated challenges from different program principal actors. At the LGU and school level, this calls for additional human capital investment on oral health professionals. Moreover, should lowerpriced generic toothpaste be made available to the public, measures to ensure that manufacturers remain unengaged in any form of commercial strategies must be in place. In ensuring affordability, manufacturers are entangled with the costs incurred from sufficiently fluoridating toothpaste and cost-efficient packaging suitable for the public. The program must also be complemented by other programs such as SALINTUBIG by the Department of Interior and Local Government (DILG), an adapted Water, Sanitation and Hygiene (WaSH) program.

Though the recommended fluoride concentration in toothpaste is $1,500 \mathrm{ppm}$, commercially available toothpaste with a seal of acceptance from the PDA still does not necessarily mean that it contains the optimal level. One possible reason is that it may incur additional costs for manufacturers. It was recommended to have a distinction for those toothpastes that meet the recommended fluoride quantity with a 'gold seal' as determined by the Food and Drug Administration (FDA). One discussant from PPDSI shared that some commercially available toothpaste marketed for pediatric patients do not contain fluoride at all, thus necessitating the need to raise public awareness and information transparency on the importance and safety of fluoride for children. This will educate the population on the 
optimal quality of toothpaste. It was also expressed that the FDA should likewise give attention to other components and abrasive particle size of toothpaste.

As a preventive strategy in oral health, the provision of fluoride products such as toothpaste and varnishes must be included in the implementation of the UHC Act to assure access to these essential oral health care products. As both can be utilized in public health programs and clinical settings, they must be recognized as population-based through the $\mathrm{DOH}$ and individual-based interventions through PhilHealth.

\section{Health Systems Financing}

Outpatient dental health services, which comprise the majority of availed oral health services, are not covered by PhilHealth benefits. PhilHealth financing of public oral health services should also be considered. The dental health team may be compensated for services rendered. This could be an encouragement for dental professionals to be in the public health sector as financial benefits can complement the services they render to the public.

As discussed in the round table discussion, PhilHeath financing of fluoridated toothpaste for public health programs across all life stages by the DOH, DSWD, and DepEd must be vigorously pursued. Fluoridated toothpaste must be recognized as a public good and not just a cosmetic product due to its caries preventive effects. Tax reliefs or exemptions may be further applied due to its public health benefits.

However, the shift in financing scheme through the Special Health Fund and the province-level integration of the health system brought by the UHC Act will change the landscape of health service delivery, including oral health services. As part of the strengthening of primary care, fluoridated products (i.e., toothpaste and varnishes) could be considered to be included in the provision of goods, provided that it would be under the population-based services through DOH. But fluoride varnish application should also be included as an individual-based preventive service that is covered by PhilHealth. Meanwhile, legitimacy of funds appropriation for comprehensive services is stipulated in Section 6 of the Act that "every Filipino shall be granted immediate eligibility and access to preventive, curative, ... dental, mental, and emergency health services, delivered as either population-based or individual-based services." ${ }^{13}$ These provide a solid base on the availability and financial accessibility of oral health services under the UHC Act.

\section{Leadership and Governance}

Oral health is a significant public health challenge. The RTD discussants pointed out that the high prevalence of dental caries will not dramatically drop, given the country's current efforts to address the problem. The current oral health status of Filipinos should be elevated and considered a public health problem.

A continuing effort in the pipeline of improving oral health governance is updating the $\mathrm{NPOH}$. The $\mathrm{DOH}$ has started the inter-sectoral process in 2015 to draft updates to the current oral health issuance. This is a continuous process as the $\mathrm{DOH}$ is expected to craft additional issuances to support the implementation of the UHC Act after its Implementing Rules and Regulations was released last October 2019.

During the discussion, one participant from the national government agency raised that the Executive Branch of the government is also geared towards investing on oral health for the population by reconstituting an Oral Health Unit in DOH after the Bureau of Dental Health Services was scrapped in 1998 due to the Department's reorganization. ${ }^{17}$ To mobilize the plan, commitment to financial support for program implementation was guaranteed, with further details to be finalized by the technical working group. This heralded that the oral health prioritization of the government is improving as it is recognized as a public health concern. The inclusion of excise taxes on sweetened beverages under the TRAIN Act of 2017 is also seen as another option to keep funds for oral health programs sustainable.

It was a consensus that policies must strive to reduce the prevalence rate of dental caries by $30 \%$ from $87.4 \%$ in 2011. To reach this 30\% target reduction of dental caries prevalence nationwide in three (3) years, comprehensive implementation and scoped plan involving LGUs, DOH, DSWD, and DepEd should be supported by funding and workforce resources.

\section{RECOMMENDATIONS}

Based on the current review of literature, experiences, and programs of the discussants, the following are recommended:

1. Target 30\% reduction in three (3) years from the $87.4 \%$ prevalence of dental caries in 2011 through the collaboration of different national to local government units, academe, professional societies, industry, private sector, and non-government organizations.

2. Focus on public health intervention and local implementations through preventive programs. Engage the academe and other training institutions in expanding the workforce of dentists and other oral health ancillaries, and develop their competencies geared towards prevention rather than curative actions. Moreover, consider the crucial roles of midwives, ob-gyne, pediatricians, school administrator, primary school teachers, barangay health workers (BHWs), to name a few, in prevention and health promotion. Start prevention at the prenatal stage through maternal and child care programs since dental caries is a behavioral disease.

3. Oral health programs to be implemented under the UHC Law should include provisions for fluoridated toothpaste in both individual-based and populationbased services. Optimal fluoride levels must be indicated in the specifications to facilitate the procurement process, as stipulated in RA 9184. 
a. Reduce consumption of sugar according to the following international standards: ${ }^{18,19}$, No fruit juice intake for children under 1-year-old;

b. Reduce sugar intake to less than $5 \%$ of total energy intake for children 4 to 8 -years old;

c. Reduce sugar intake to less than $10 \%$ of total energy intake for children above 8-years old; and

d. Reduce sugar intake to less than 6 tablespoons daily for children 2-18 years old. ${ }^{20}$

4. Research on safety and effectiveness, affordability, and viability to aid in monitoring the quality and costeffectiveness of commercially available toothpaste for relevant health technology assessment as stipulated in Sec. 34 of the UHC Act.

5. Change the maldistribution of oral health professionals. Incentivize through salary, CPD units, and involvement in urban to rural setting practices.

6. Ensure sufficient funds for the sustainability of national oral health programs. Consider accessing excise tax on sugary beverages.

7. Constitute a technical working group to discuss further the implementation details of recommended policies leaning towards operationalization.

8. Extend the engagement of dental professionals from the individual- to population-based services in light of strengthening primary care under the UHC Act.

9. Engage dental professionals in the prevention and control of non-communicable diseases through the incorporation of oral health programs in non-communicable disease health strategies.

\section{Statement of Authorship}

All authors participated in data collection and analysis, and approved the final version submitted.

\section{Author Disclosure}

All authors declared no conflicts of interest.

\section{Funding Source}

This project was funded by the DOST DOH AHEADHPSR.

\section{REFERENCES}

1. National Policy on Oral Health, Department of Health Administrative Order 101, s. 2003.

2. Wahlström S. National Monitoring and Evaluation Dental Survey (NMEDS) [Internet]. 2011 [cited 2018 Jul 31]. Available from: https://www.mah.se/CAPP/Country-Oral- Health-Profiles/WPRO/ Philippines/Oral-Diseases/Dental-Caries/.

3. World Health Organization. Strategy for oral health in South-East Asia, 2013-2020. 2013.
4. Van Palenstein Helderman W, Holmgren C, Monse B, Benzian H. Caries Prevention and Control in Low- and Middle Income Countries. In: Fejerskov O, Nyvad B. Dental Caries - The Disease and its Clinical Management, 3rd ed. Wiley Blackwell; 2015.

5. Guidelines in the Implementation of Oral Health Program for Public Health Services, Department of Health Administrative Order 20070007. (2007).

6. Department of Health. Dental Health Program [Internet]. nd [cited $2018 \mathrm{Jul}$ 20]. Available from: https://www.doh.gov.ph/dental-healthprogram.

7. Department of Education. DO 73, s. 2007 - Promoting Oral Health in Public Elementary Schools [Internet]. October 16, 2017. [cited 2018 Jul 20]. Available from: https://www.deped.gov.ph/2007/10/16/ do-73-s-2007-promoting-oral-health-in-public-elementary-schools/

8. Mendoza MAF. Call to Action for the Oral Health of Filipinos. J Philipp Dent Assoc. 2018; 65(1):41-3.

9. FDI World Dental Federation. Oral health and noncommunicable diseases [Internet]. 2019 [cited 2018 Jul 20]. Available from: https://www.fdiworlddental.org/what-we-do/advocacy/oral-healthand-noncommunicable-diseases

10. World Health Organization [Internet]. Monitoring the Building Blocks of Health Systems: A Handbook of Indicators and Their Measurement Strategies. 2010 [cited 2018 Oct 15]. Available from: http://www.who.int/healthinfo/systems/monitoring/en/.

11. Implementation Of Essential Health Care Program (Ehcp) For The School Children, DepEd Order No. 65, s. 2009.

12. Happy Smiles for Healthy Kids Project, DepEd Memorandum 78, s. 2011 [Internet]. 2011 [cited 2018 Jul 25]. Available from: http://www. deped.gov.ph/2011/03/25/march-25-2011-dm-78-s-2011-happysmiles-for-healthy-kids-project.

13. Department of Health. National Oral Health Survey (NOHS) [Internet]. 2006 [cited 2018 Jul 20]. Available from: http://www.doh. gov.ph/dental-health-program.

14. Republic of the Philippines. Republic Act 11223. An Act Instituting Universal Health Care for All Filipinos, Prescribing Reforms in the Health Care System, Amending for The Purpose Certain Laws, Appropriating Funds Therefore and for Other Purposes; 2018.

15. World Health Organization [Internet]. Global Health Observatory Data [Internet]. 2018 [cited 2018 May 11]. Available from: http:// www.who.int/gho/en/.

16. Professional Regulation Commission. Resolution No. 1146 Series of 2019. Amending Relevant Provisions of Resolution No. 1032 (s. 2017), otherwise known as the "Implementing Rules and Regulations (IRR) of Republic Act No. 10912 known as the Continuing Professional Development (CPD) Act of 2016."

17. Reyes BP. The Dental Health Services after DOH Re-Engineering (Progressive or Retrogressive Act?). J Philipp Dent Assoc. 2001; 53(2):27-33.

18. American Academy of Pediatrics. American Academy of Pediatrics Recommends No Fruit Juice For Children Under 1 Year [Internet]. 2017 [cited 2018 Jul 20]. Available from: https://www.aap.org/enus/about-the-aap/aap-press-room/Pages/American-Academy-ofPediatrics-Recommends-No-Fruit-Juice-For-Children-Under-1Year.aspx.

19. American Academy of Pediatric Dentistry. Policy on Dietary Recommendations for Infants, Children, and Adolescents [Internet]. Oral Health Policies. 2017 [cited 2018 Nov 21]. Available from: http:// www.aapd.org/media/policies_guidelines/p_recdietary.pdf.

20. American Heart Association. Sugar Recommendation Healthy Kids and Teens Infographic [Internet]. n.d. [cited 2018 Nov 21]. Available from: https://www.heart.org/en/healthy-living/healthy-eating/ eat-smart/sugar/sugar-recommendation-healthy-kids-and-teensinfographic. 